\title{
Common issues, different approaches: strategies for community-academic partnership development
}

\author{
Janet M Baiardi, a Barbara L Brushb and Sharon Lapidesc \\ aUniversity of Detroit Mercy, Detroit, Ml, bUniversity of Michigan, Ann Arbor, MI, cCommunity and Home Supports, Inc., \\ Detroit, MI, USA
}

Accepted for publication 9 July 2010

BAIARDI JM, BRUSH BL and LAPIDES S. Nursing Inquiry 2010; 17: 289-296

Common issues, different approaches: strategies for community-academic partnership development

Communities around the United States face many challenging health problems whose complexity makes them increasingly unresponsive to traditional single-solution approaches. Multiple approaches have considered ways to understand these health issues and devise interventions that work. One such approach is community-based participatory research. This article describes the development of a new collaborative partnership between a school of nursing and an urban social service agency using community-based participatory research as a framework. We describe the partnership's evolution and process of data collection and analysis and evaluate the outcomes of both. We argue that community-based participatory research involves partnerships at its core whose members, both as individuals and part of the collaboration, must be committed and nimble in the face of shifting and challenging health and social problems, recognize common issues and concerns across the boundaries of community and academia, and respect each other's different approaches and expertise.

Key words: action research, community, participatory action research.

Communities around the United States (US) face many challenging health problems whose complexity makes them increasingly unresponsive to traditional single-solution approaches (Green and Mercer 2001). Multiple approaches have considered ways to understand these health issues and devise interventions that work. One such approach is community-based participatory research (CBPR) (Minkler and Wallerstein 2003; Wells et al. 2006). Rooted in critical theory and constructivist paradigms (Israel et al. 1998), CBPR emphasizes collaboration, engagement, and social capital between communities such as service agencies and researchers to create best practice models for community health problems (Levy, Baldyga, and Jurkowski 2003; Jones and

Correspondence: Janet M. Baiardi, McAuley School of Nursing, University of Detroit Mercy, 4001 W. McNichols, Detroit, MI 4822I, USA.

E-mail: <baiardjmudmercy.edu>
Wells 2007; Norris et al. 2007). The idea is that through pooling resources, mobilizing each other's best talents, and diversifying approaches, interventions can be designed and implemented that improve health outcomes in traditionally underserved communities within which wide health disparities exist (Mitchell and Shortell 2000). Despite this ideal and national initiatives aimed at eliminating health disparities (US Department of Health and Human Services 2000), there remain few interventions that effectively reduce health disparities (Villarruel 2004). Much of this failure stems from a general lack of understanding about how CBPR partnerships are created and sustained over time.

In this article, we describe the development of a new collaborative partnership between two schools of nursing and an urban social service agency serving homeless families and homebound older adults in Detroit, Michigan which occurred over a 12-month period. The aims of the partnership were to develop an understanding of the community's 
immediate needs by actively engaging the community served in the research process and to build capacity for a sustainable partnership that would identify research priorities and design program initiatives for future collaboration. We describe the use of CBPR as a framework for grassroots engagement, the partnership's evolution, the process of data collection and analysis, the outcomes of our collaborative research efforts, and lessons learned.

\section{PRINCIPLES AND PROBLEMS WITH CBPR}

For research to translate into effective clinical applications, it must first address the needs of diverse communities and be accepted by the community itself. Embraced by many researchers as a methodological avenue to these aims, CBPR involves partners equally in the research process so that they can create culturally sensitive interventions to meet the needs of community stakeholders (Baker et al. 1999; Dancy et al. 2004; Bruce and Austin-Ketch 2006; Fowles 2007). Within CBPR, there is recognition that partners bring different skills, information, ideas, and talents to the table so that new resources, new programs, or new methods can be applied and measured in new ways. Despite this inclusive approach, however, partnerships can be fraught with difficulty, including trust issues, conflicting agendas, and unequal power dynamics that thwart its ability to achieve significant, measurable outcomes (Butterfoss and Francisco 2004). Those most likely to sustain themselves over time tend to operate in an atmosphere of open communication (Freimuth et al. 2001; Dancy et al. 2004) built upon mutually beneficial goals (Di Bari et al. 2007), a decrease in power differentials (Cricco-Lizza 2007), and clear strategies to empower the community. Trust is inherent in the process, requiring a significant time investment (Earl and Penney 2001; Cohn 2007; Shaya et al. 2007) and repeated consistent interactions (Corbie-Smith, Thomas, and St George 2002).

\section{DEVELOPING THE COMMUNITY- ACADEMIC PARTNERSHIP}

With the tenets of CBPR firmly in mind, a community-academic partnership was established between faculty researchers from two schools of nursing and a non-profit social service agency located in Detroit, Michigan. The agency's two major programs are directed toward providing assistance with housing and other services (i.e. case management, life skills management, employment counseling) to homeless families (primarily women and children) as well as direct care services to older adults residing at home. While these efforts have proven effective in securing housing or keeping people housed, the agency expressed interest in expanding its efforts to include health promotion activities. The agency's vice president of programs, a master's prepared social worker with extensive experience in community organization and partnerships, was the contact person for the agency. The nurse researchers/academicians were experts in clinical research and practice with urban homeless populations (Brush and McGee 1999, 2000; Brush and Powers 2001) and community-dwelling older adults.

The notion of a partnership evolved after a series of informal meetings to discuss areas of mutual interest and concern. These meetings also provided an opportunity for the partners to begin to understand one another and how similar and differing perspectives needed to be considered early on in partnership development. It became immediately apparent, for example, that the academic partners wanted to forge a community-based research program with measurable long-term outcomes while the community partner was primarily interested in program development and grantsmanship to support continued sustainability in the more immediate future. Although all wanted to improve access to quality services for the population served, different pressures dictated different foci that each needed to appreciate and consider. For example, the community partner was more concerned with maximizing services with shrinking resources while the academic partners' lens was directed at rigorous scientific inquiry. Aligning these perspectives into a shared goal was critical at the onset.

With a clearer notion of the focus and goals from both academic and community agency perspectives, the initial 3 member group submitted for, and was awarded funding to pilot a one-year project aimed at partnership development. A secondary aim was to ascertain the community's perspectives about their health care needs and the role of research in addressing them. We proposed using focus groups to meet our second aim, and, recognizing that the community agency's focus on housing for homeless families and homebased caregiver services for older adults were different in purpose, scope and personnel, opted to collect data and analyze these groups separately. To garner a fuller understanding of the health and service perceptions of the community served, we proposed the inclusion of both service providers and service recipients from each program. Thus, for example, we proposed one focus group for homeless program case workers and one focus group for homeless participants. Likewise, we proposed one focus group for the direct service providers and one for the older adult care-recipients in the older adults program. After an initial meeting with each of the four groups, we then proposed a follow-up focus group to review our thematic interpretation of their dialogue, 
clarify any misunderstandings, and invite further discussion as the group deemed important.

One of our initial steps in partnership development was to hire a project manager (PM) from within the community organization. This decision was viewed by the partnership as essential to increase the trust building necessary for ongoing success. Project managers tend to be supplied from the academic side as they are often more seasoned in research and grant activities. In contrast to this, and adhering to the premise of CBPR, we ascertained that the PM should be directly linked to the community partner and known and trusted by those inside the partner agency (Christopher et al. 2008). At this stage of the process in partnership development, we deemed the PM's first-hand knowledge and expertise of the community to be more important to the project's success than her research expertise (Casey 2008). The PM would thus serve as a liaison between the researchers, agency administrators, and members of the community; facilitate project activities with an insider's perspective; and, in response to the concerns of the community co-investigator, shift needed resources from the grant toward the agency's immediate sustainability needs.

\section{COMMUNITY ADVISORY BOARD}

As a critical step in the process of community engagement (Di Bari et al. 2007), we next established a community advisory board $(\mathrm{CAB})$ to work with the project team. Though inherently time consuming because of the need to engage with numerous individuals on a regular and consistent basis, community advisory boards provide the framework for creating sustainable community-academic partnerships (Alvarez and Gutiérrez 2001), maximizing trust (Dennis and Neese 2000) and scientific rigor (Topp, Newman, and Jones 2008). Given the literature supporting the use of community workers as effective community change agents, we invited two individuals working on the front lines with the community to serve on the $\mathrm{CAB}$. This strategy aimed to include individuals with unique perspectives who could facilitate trust and engagement between researchers and the community and increase power sharing between the academic and community partners (Ammerman et al. 2004; Andrews et al. 2004; Benoit et al.2005). These members (one who worked with the homeless program and the other with older adult services) were selected because of their credibility within the target community, their ability to facilitate communication between partners, and their willingness to serve. To round out academic and community participation and level of expertise, we also invited as members of the CAB, an undergraduate nursing student and an administrator from a community agency who subcontracted with the partner agency.

The purpose of the $\mathrm{CAB}$ was to develop the strategic plan for the partnership, review all content and materials related to the partnership and its data collection/research goals, evaluate the project's ongoing integrity, and determine longrange goals for research development and community interventions. Our plan was that the $\mathrm{CAB}$ would transition to a research advisory group (RAG) at the conclusion of the pilot year. The RAG's focus would be the continued sustainability of the partnership and research activities to address community needs, grantsmanship and continued scholarship dissemination. We anticipated that some members of the $\mathrm{CAB}$ might elect to remain on the RAG while others transitioned out and new people were added.

Working on the premise that relationships require frequent and consistent interactions, the $\mathrm{CAB}$ began to meet prior to the funding decision in an effort to establish a trusting relationship between its members. Early conversations centered on the role of the $\mathrm{CAB}$, the purposes of the partnership, and the overall aims of the pilot project. At the first meeting, a timeline of monthly $\mathrm{CAB}$ meetings was scheduled and a process for minute distribution and electronic communication was established.

When funding ensued a month later, the early foundation of relationship building within the $\mathrm{CAB}$ proved beneficial; the partner agency underwent a significant organizational change that included cost-cutting measures that eliminated the project's community co-investigator. The implications of this were discussed with the $\mathrm{CAB}$ in an effort to maintain open communication. We recognized that individuals play a key role in partnership growth in its early stages and losing a key player threatened the partnership's integrity from its inception. Fortunately, a solution emerged. The community co-investigator was able to organize and take leadership of a new community organization and assume oversight of the homeless and adult caregiver programs from the former agency. Flexibility of CBPR was reflected in the relatively easy transition to a partnership with the newly formed community agency. Although the transition required a shift in $\mathrm{CAB}$ membership (one of the original members from the community partnership did not move with the reorganization and the undergraduate nursing student had a change in academic responsibilities and had to resign), we invited another community member from a non-profit agency that works closely with the partner agency and a graduate student in public health with an interest in urban populations to join the $\mathrm{CAB}$. Thus, the work of the $\mathrm{CAB}$ and the project were able to move forward in conjunction with our originally proposed timeline. 


\section{IMPLEMENTING THE PILOT}

During the first several meetings of the newly realigned $\mathrm{CAB}$, a shared vision and common goals were re-established. Although the agency provided services to both homeless families and homebound older adults, these programs were very different and the direct service providers working in them had little, if any, contact with one another. The CAB wanted to learn more about the vulnerable populations they served as well as more about each other. Thus, early meetings of the $\mathrm{CAB}$ proved significant in clarifying understandings and engaging new roles and directions for its members. For example, the community partner members were unfamiliar with some of the roles of the nurse researcher faculty members. One $\mathrm{CAB}$ member later disclosed, 'we thought at first you were here to take our jobs'. It was only after repeated interactions and open communication that they acknowledged this initial level of distrust. Likewise, the academic members of the project team came to understand that advisory group membership was a new experience for most of the community members. More accustomed to carrying out job responsibilities than offering opinions and advice, many were at first reticent to express their views around the table or answer questions unless asked directly. The researchers needed to convey that the expertise of the community partners was both valued and needed and act accordingly.

With funding and institutional review board (IRB) approval in hand, we moved forward with the research component of the project. The CAB participated in all aspects of focus group preparation, including devising strategies for subject recruitment and means to incentivize participation, to fine tuning the semi-structured interview guide to best address the varied community cohorts. For example, CAB members identified participant recruitment as a potential challenge for the study. In our original design, the project team and $\mathrm{CAB}$ members envisioned four 6-person focus groups with a second follow-up focus group in 4-6 weeks for the purpose of validating findings and interpretation. The community $\mathrm{CAB}$ members were particularly concerned that recruiting direct service providers from the older adult program and the older adults themselves would be problematic. They knew that the service providers generally worked from home rather than from a central office, were paid on an hourly basis, and had varied schedules that might compromise a shared meeting time. They also knew that bringing older adults to a central place for both an initial and followup focus group would be difficult, not just logistically but because of fear and trust issues.

Based on the CAB's input, the design was reconceptualized so that the number of focus group participants in each group increased from 6 to 8 participants and met only once for an extended time period. The $\mathrm{CAB}$ members suggested that we hold the direct service provider focus group at a time when they would be participating in a mandatory training meeting at a central location. That way, individuals who chose to participate would be near the location and receive reimbursement for their parking. They also suggested that we provide lunch along with the gift card incentives to express our appreciation of their time. To advertise the focus group, we created a flyer that attached to the service providers' weekly paychecks over a 3-week period and asked them to contact the PM if interested. With these suggestions implemented, not only did we have ample recruitment but we had to limit the focus group to a first-come first-served basis.

We held our focus group for older adults in an apartment building where many of the agency clients resided. The $\mathrm{CAB}$ deemed this to be the best option for bringing older adult service recipients together. Many of the individuals knew each other, at least tangentially, and shared a common living space. This, the CAB members argued, would encourage participation because the participants would be secure in their own environment, would not need to travel elsewhere, and shared a common bond with other focus group members. In addition, many of the older adults had health problems and/or physical mobility limitations that might create safety concerns. While this strategy was less methodologically sound (it limited our understanding of experiences of individuals who were more isolated in individual homes), it provided a means for early exploration from which we could address issues and concerns. Again, recruitment proved unproblematic and we had a successful focus group with seven individuals from this cohort.

We were able to recruit and hold initial and follow-up focus groups with the homeless program service providers and homeless service recipients. Because the service providers worked from a central office location, the CAB members did not anticipate problems with either recruitment or access. They encouraged us; however, to schedule times that willing subjects did not view as extra work or an extended work day. Providing food along with gift cards, they argued again, would entice more participation. We negotiated with the agency administration and were able to hold the focus groups for service providers during an extended lunch period without penalty to the participants. This strategy worked; again advertising with a flyer in weekly paychecks, we had more than the anticipated interest and increased the focus group size to accommodate additional persons $(n=8)$.

Because the recipients of the homeless programs did not share a central living space and were located widely across 
the community, we relied heavily on the community $\mathrm{CAB}$ member affiliated with the program to help with recruitment. We were told that we would fare better if we provided participants with transportation costs to and from their current living arrangements. We also co-ordinated focus group times with a program for life skills that many service recipients attended. We asked individual service providers to advertise our interest to potential subjects and, anticipating the potential for no-shows, recruited 8 participants. Despite our best efforts, only 3 individuals showed up for the first focus group session.

The academic researchers, along with the project manager, analyzed the transcripts independently to identify overall themes. The researchers then used an iterative process to clarify thematic choices and reach group consensus. These themes were then brought back to the CAB for discussion. Participant anonymity was carefully maintained since many of the participants would be known by $\mathrm{CAB}$ members.

In our second focus groups with homeless program service providers and later with service recipients we had $100 \%$ return rates. Individuals in each of those groups shared their feelings of 'feeling heard' and wanted to continue to participate so that others facing similar situations would benefit. It was clear that the knowledge brought by the community partner $\mathrm{CAB}$ members was instrumental in the implementation phase and helped engender trust in the community.

\section{LESSONS LEARNED}

Researchers describe multiple challenges to CBPR (Israel et al. 1998; Baker et al. 1999; Minkler 2005; Shoultz et al. 2006; Casey 2008). These include issues related to partnership development, ethics, research methods, and infrastructure issues. Despite the successes of our partnership and pilot work, there were several challenges that require further evaluation and reflection.

The first challenge, was the organizational change that occurred shortly after initiation of the partnership and $\mathrm{CAB}$ development. The loss of a significant stakeholder might have hastened dissolution of the partnership. The commitment of the partnership members and their willingness to be nimble, however, were essential ingredients needed to move forward. Described by Hubbell and Burman (2006) as the ability to balance ongoing tensions, this early challenge and success was a springboard to the partnership's continued development.

As we neared completion of the data collection phase of the project, we began to notice another challenge; two of the $\mathrm{CAB}$ members who had been instrumental in helping design and implement focus group strategies began to disengage from the group. These were the community agency members with expertise in the service programs. We noticed that over time, although both continued to regularly attend meetings, they became less verbal and seemingly less interested. This was particularly true when data were disseminated for discussion. Several attempts were made to discuss interest and engagement during the $\mathrm{CAB}$ meetings when group dynamics were evaluated, but neither offered feedback. At the end of the year-long project, one of the community members handed the PM her resignation from the CAB and the other member's position within the organization was eliminated.

We continued to reflect on the situation in an effort to evaluate the group's behavior and interaction. The member who resigned reported to the PM that she had wanted to play a larger role in the research process but was uncomfortable verbalizing openly. This brought an interesting issue to the forefront that we had not anticipated. While we were aware of, and continuously monitored, the power differentials between the community and academic partners, we failed to recognize the natural power differential that can occur within an organization. This is especially true when some members of the process hold subordinate roles in the organization. This is an unavoidable situation if CBPR is to be implemented in its truest form, but one that must be consciously acknowledged. Future efforts must address this concern at the partnership's onset and be continually reinforced so that each member feels safe and supported.

We also recognize that while we realized that research preparation, expertise and experience between the $\mathrm{CAB}$ members differed, we did not clearly offer to expand individuals' roles outside of their initial areas of preparation, expertise, or experience. That is, while we sought the expertise of the community members for their knowledge of the community and the programs, and shared findings and strategies for ongoing research, we did not consider capacity building and skill development that they may have wanted but were unable to discuss. Perhaps when the community members felt their expertise was tapped to its full extent, they began to disengage from the process. In the future, we would raise this potential disengagement up front and invite $\mathrm{CAB}$ members to fully articulate their individual goals for participation along with their goals for group involvement.

Our attention on group cohesiveness, trust, and inclusivity, therefore, might have actually marginalized individuals in the process. Indeed, we came to recognize that individual efforts within the group dynamic are vital to the partnership's overall success. For example, the project manager was 
integral to both the success of the partnership and the pilot work. Her direct linkage to the community organization was crucial to maintaining lines of communication and navigating systemic and personal boundaries. That grant funding supported a portion of her salary and defrayed costs to the organization, also enhanced her role as a community liaison and affected greater power-sharing between the community and academic partners. Toward the project's conclusion, the PM left the organization to pursue full-time graduate studies. Though a loss to the CAB because of her hard work, dedication, and commitment, it is clear that the next PM needs to share the same attributes and hold good standing in the community.

A final challenge that should be acknowledged is that many partnerships evolve after or as a result of successful grant submissions. As we have noted, our grant proposal was submitted prior to $\mathrm{CAB}$ development. Our design and methods were informed by the literature yet naive in their practicality with the population served by the agency. The $\mathrm{CAB}$ helped us significantly reframe our approach to more successful ends. We anticipate that our future proposals, written with input from the newly formed research advisory group (RAG), will be much more informed from their inception.

\section{CONCLUSION}

The pilot initiative provided a foundation for the development of a sustainable partnership that moved forward in a constantly shifting, and often challenging, environment. The CAB transitioned to a larger, more diverse RAG whose membership also expanded on both community and academic sides. With the original partnership intact, new efforts include networking with other agencies and community-academic partnerships to expand the depth and breadth of CBPR in communities with shared interests and mutual goals. Data collected from our focus groups forms the foundation of many of these efforts; through dissemination, other agencies seeking academic partners have contacted us to help gather evidence towards creating translational best practice models.

We recognize that CBPR is a constantly moving target that requires nurturing and elasticity befitting ever changing health and social systems. Whether in the United States or communities across the globe, or between various interdisciplinary researchers and/or type of communities, problems in the community are dynamic and, as such, require approaches that can adapt and evolve with them. Nurses and other health care providers, who are ideally positioned to do this type of research given their long standing practice and service in the community, need to be particularly mindful of adhering to a systematic approach to maximize efficacy and sustainability. Partnership success likewise depends on the willingness and commitment of its members to share power and expertise as well as address potential pitfalls along the way. Recognizing our common issues and respecting our different approaches is the first step along the path to that success.

\section{ACKNOWLEDGEMENTS}

This project was supported by funding from the National Center for Research Resources (Grant UL1RR024986) and from the Michigan Institute for Clinical and Health Research (5P30 NR009000).

\section{REFERENCES}

Alvarez A Rosegrant and Lorraine Gutiérrez. 2001. Choosing to do participatory research: An example and issues of fit to consider. Journal of Community Practice 9: 1-19.

Ammerman Alice, Giselle Corbie-Smith, Diane M St George, Chanetta Washington, Beneta Weathers and Bethany Jackson-Christian. 2004. Research expectations among African American church leaders in the PRAISE! Project: A randomized controlled trial guided by communitybased participatory research. American Journal of Public Health 93: 1720-7.

Andrews Jeanette $\mathrm{O}$, Gwen Felton, Mary Ellen Wewers and Jane Heath. 2004. Use of community health workers in research with ethnic minority women. Journal of Nursing Scholarship 36: 358-65.

Baker Elizabeth A, Sharon Homan, Rita Schonhoff Sr and Matthew Krueter. 1999. Principles of practice for academic/practice/community research partnerships. American Journal of Preventative Medicine 16(3S): 86-93.

Benoit Cecilia, Mikael Jansson, Alison Millar and Rachel Phillips. 2005. Community-academic research on hardto-reach populations: Benefits and challenges. Qualitative Health Research 15: 263-82.

Bruce Susan A and Tammy Austin-Ketch. 2006. Communitybased participatory research: An exemplar of learning. American Journal for Nurse Practitioners 10(7/8): 24-8.

Brush Barbara L and Eileen M McGee. 1999. The Expanded Care for Healthy Outcomes (ECHO) Project: Addressing the spiritual care needs of homeless men in recovery. Clinical Excellence for Nurse Practitioners 3: 116-22.

Brush Barbara L and Eileen M McGee. 2000. Evaluating the spiritual perspectives of homeless men in recovery. Applied Nursing Research 13: 181-6.

Brush Barbara L and Emily M Powers. 2001. Health and service utilization patterns among homeless men in transi- 
tion: Exploring the need for on-site, shelter-based nursing care. Scholarly Inquiry for Nursing Practice 15: 14354.

Butterfoss Frances D and Vincent T Francisco. 2004. Evaluating community partnerships and coalitions with practitioners in mind. Health Promotion Practice 5: 108-14.

Casey Mary. 2008. Partnership-success factors on interorganizational relationships. Journal of Nursing Management 16 : 72-83.

Christopher Suzanne, Vanessa Watts, Alma Knows His Gun McCormick and Sara Young. 2008. Building and maintaining trust in a community-based participatory research partnership. American Journal of Public Health 98: 1398406.

Cohn Elizabeth G. 2007. Including marginalized populations in HIV clinical trials: A new role for nurse-researchers. Policy, Politics and Nursing Practice 8: 271-5.

Corbie-Smith Giselle, Stephen B Thomas and Diane M St George. 2002. Distrust, race and research. Annals of Internal Medicine 162: 2458-63.

Cricco-Lizza Roberta. 2007. Ethnography and the generation of trust in breastfeeding disparities research. Applied Nursing Research 20: 200-4.

Dancy Barbara L, JoEllen Wilbur, Marie Talashek, Gloria Bonner and Cynthia Barnes-Boyd. 2004. Communitybased research: Barriers to recruitment of African Americans. Nursing Outlook 52: 234-40.

Dennis Betty P and Jane B Neese. 2000. Recruitment and retention of African-American elders into communitybased research: Lessons learned. Archives of Psychiatric Nursing 14: 3-11.

Di Bari Mauro, Patricia K Suggs, Latonia P Holmes, Deborah F Farmer, Sharon W Williams, Marco Pahor and Sharon A Jackson. 2007. Research partnership with underserved African-American communities to improve the health of older persons with disability: A pilot qualitative study. Aging Clinical and Experimental Research 19: 110-8.

Earl Catherine E and Pamela J Penney. 2001. The significance of trust in the research consent process with African Americans. Western Journal of Nursing Research 23: 753-62.

Fowles Eileen R. 2007. Collaborative methodologies for advancing the health of underserved women. Family Community Health 30(1S): S53-63.

Freimuth Vicki S, Sandra C Quinn, Stephen B Thomas, Galen Cole, Eric Zook and Ted Duncan. 2001. African Americans' views and the Tuskegee Syphilis Study. Social Science and Medicine 52: 797-808.

Green Lawrence W and Shawna L Mercer. 2001. Can public health researchers and agencies reconcile the push from funding bodies and the pull from communities? American Journal of Public Health 91: 1926-8.

Hubbell Kelly and Mary E Burman. 2006. Factors related to successful collaboration in community-campus partnerships. Journal of Nursing Education 45: 519-22.

Israel Barbara A, Amy J Schulz, Edith A Parker and Adam B Becker. 1998. Review of community based research: Assessing partnership approaches to improve public health. Annual Review of Public Health 19: 173-202.

Jones Loretta and Kenneth Wells. 2007. Strategies for academic and clinician engagement in community-participatory partnered research. Journal of the American Medical Association 297: 407-10.

Levy Susan R, William Baldyga and Janine M Jurkowski. 2003. Developing community health promotion interventions: Selecting partners and fostering collaboration. Health Promotion Practice 4: 314-22.

Minkler Meredith. 2005. Community-based research partnerships: Challenges and opportunities. Journal of Urban Health 82(Supplement 2): ii3-ii12.

Minkler Meredith and Nina Wallerstein eds. 2003. Community-based participatory research for health. San Francisco, CA: Jossey-Bass.

Mitchell Shannon M and Stephen M Shortell. 2000. The governance and management of effective community health partnerships: A typology for research, policy, and practice. The Milbank Quarterly 78: 241-89.

Norris Keith C, Rebecca Brusuelas, Loretta Jones, Jeanne Miranda, Kenrick Duru and Carol M Mangione. 2007. Partnering with community-based organizations: An academic institution's evolving perspective. Ethnicity and Disease 17: S1-27.

Shaya Fadia T, Confidence M Gbarayor, Huiwen K Yang, Mariette Agyeman-Duah and Elijah Saunders. 2007. A perspective on African American participation in clinical trials. Contemporary Clinical Trials 28: 213-17.

Shoultz Joy, Mary Frances Oneha, Lois Magnussen, Mya M Hla, Zavi Brees-Saunders, Marissa Dela Cruz and Margaret Douglas. 2006. Finding solutions to challenges faced in community-based participatory research between academic and community organizations. Journal of Interprofessional Care 20: 133-44.

Topp Robert, Jamie L Newman and Veronnie F Jones. 2008. Including African Americans in health care research. Western Journal of Nursing Research 30: 197-203.

US Department of Health and Human Services. 2000. Healthy people 2010: Understanding and improving health. 2nd edn. Washington, DC: US Government Printing Office. http://www.healthypeople.gov/ (accessed on 29 November 2007). 
Villarruel Antonia M. 2004. Eliminating health disparities. Annual Review of Nursing Research 22: 1-6.

Wells Kenneth B, Anne Staunton, Keith C Norris, CHIC Council, Ricky Bluthenthal, Bowen Chung, Lillian
Gelberg et al. 2006. Building an academic-community partnered network for clinical research: The community health improvement collaborative (CHIC). Ethnicity $\mathcal{F}^{\circ}$ Disease 16: S1-3-17. 